\section{perifèria}

Número 18(2), diciembre 2013

http://revistes.uab.cat/periferia

\title{
De aquí para allá, sin o con caballo. Patagonia, 13.000 años de historia.
}

\author{
Laura Mameli - Universitat de Girona
}

\section{Resumen}

A lo largo de 13.000 años Patagonia estuvo ocupada por poblaciones cazadorasrecolectoras sumamente móviles, con diversificada movilidad territorial, residencial y logística. Las complejas y extensas redes sociales que constituyeron permitieron la circulación de bienes, personas e ideas, condicionando los procesos de etnogénesis y los mecanismos de fisión y fusión social. A fines del Holoceno, la naturaleza de los desplazamientos nómadas y nuevas formas de interacción social y contacto provocaron importantes transformaciones sociales y económicas que desembocaron en una mayor jerarquización social y territorialidad.

\begin{abstract}
All along its 13.000 years, Patagonia was occupied by hunter-gatherer populations highly mobile, with diversified territorial, residential and logistic mobility. The complex and extensive social networks formed allowed the movement of goods, people and ideas, conditioning ethnogenesis processes, and mechanisms of social fission and fusion. In the late Holocene, the nature of nomadic movements and new forms of social interaction and contact caused major social and economic transformations that led to greater social hierarchy and territoriality.
\end{abstract}

\section{Introducción}

Nuestra sociedad moderna, industrializada y opulenta tiende a excluir y a marginar regiones enteras del planeta. Patagonia es una de esas regiones, considerada tradicionalmente como territorio inhóspito y deshabitado. Esta noción ha ido acompañada por la marginación de las poblaciones autóctonas que en ella han vivido. Las sociedades indígenas han sufrido el impacto de la colonización europea con un resultado dramático, en tanto que este contacto provocó desplazamientos forzados, esclavización, enfermedad y muerte. 


\section{perifèria}

Número 18(2), diciembre 2013

http://revistes.uab.cat/periferia

\section{El entorno}

Si algo caracteriza el paisaje y la geografía de Patagonia es su variabilidad, un rasgo que la etnografía histórico-cultural tradicional nunca tuvo en cuenta, enfatizando una más aparente que real "pobreza" de recursos. En diferentes regiones ecológicas (costas, montañas, estepas, bosques), aunque la diversidad de recursos alimenticios pudiera haber sido escasa, estacionalmente la cantidad de masa alimenticia resultó abundante.

Debemos tener en cuenta que la dieta de un grupo humano no es una decisión condicionada directamente por la ecología, sino que debe enfatizarse la importancia de la esfera social en su determinación. En Patagonia, existieron muchos tipos de recursos explotables, pero los grupos humanos decidieron de qué especies alimentarse, qué materias utilizar, dónde, cómo y cuándo proveerse dentro del amplio abanico ofertado por ese entorno, dando mayor importancia a un pequeño subconjunto en función de finalidades alimenticias, infraestructurales, instrumentales, sociales, ornamentales, medicinales, entre otros usos.

\section{Moverse para vivir}

Más que describir un grupo humano por lo que come debemos caracterizarlo por cómo trabaja y por cómo se relaciona con otros grupos geográficamente más o menos próximos, ya sea colaborando en reciprocidad, imponiéndose o condicionando a otro grupo. En Patagonia, fue la movilidad de los agentes sociales en un territorio heterogéneo ecológicamente, y no la localización de recursos, lo que pudo haber condicionado la identidad social y cultural de las distintas poblaciones en el pasado. Los grupos cazadores-recolectores se suelen trasladar para resolver sus necesidades económicas, sociales y políticas (juntarse para cooperar), de tal manera que emergen redes de interacción extensas y complejas (Del Castillo 2012). Esto ha demostrado en los últimos años la arqueología patagónica, apuntando a que en 13.000 años, los productos del trabajo y la información habrían viajado más que las personas (Barbarena 2008, Boschín y Andrade 2011, Gómez-Otero 2007, Moreno 2008, Prates 2008). Borrero y otros 


\section{perifèria}

Número 18(2), diciembre 2013

http://revistes.uab.cat/periferia

(2008) explican la circulación de bienes a larga distancia en radios que se superponen parcialmente y cuya extensión se debe a factores económicos y sociales que harían que las relaciones entre los grupos fuesen fluidas a lo largo del tiempo.

Esas redes de interacción, así como la vinculación política entre individuos y grupos, tuvieron gran importancia en la diversificación cultural de grupos humanos. La historia de las poblaciones indígenas de Patagonia es resultado de distintas formas de interacción social, con fisión y segregación de grupos, y fusión en grandes unidades sociales y políticas, más o menos centralizadas. Lejos de tratarse de bandas deambulando a la búsqueda y captura de alimento, debemos considerarlos en tanto que un conglomerado de distintos grupos humanos que construyeron una compleja forma de vida que incluía la explotación de distintos y variados recursos en distintos lugares, lo que favoreció el contacto entre gentes, difundió ideas, productos e innovaciones.

\section{La primera presencia humana}

La información paleobiológica permite inferir un poblamiento caracterizado por la movilidad residencial, el desplazamiento entre distintas zonas ecológicas y el intercambio de bienes, ideas y personas (Pérez 2011). Suele considerarse la existencia de rangos de movilidad estacional que podrían haber implicado la ocupación de lugares cercanos a la cordillera en verano, y a la costa en invierno. El hallazgo arqueológico de valvas marinas en la cordillera pone de manifiesto la existencia de circulación de bienes, con intercambios a grandes distancias; en este caso de hasta $400 \mathrm{~km}$. Las semejanzas en el arte rupestre, y su posible vinculación a lugares de paso se ha utilizado como prueba de estas formas de interacción social.

De ahí que se pueda interpretar que el flujo génico entre poblaciones estuvo probablemente condicionado por la distancia geográfica entre diversas comunidades y las crecientes diferencias económicas, sociales y culturales. Ello podría haber provocado alrededor de 5.000 años de aislamiento en el extremo sur, frente a un 


\section{perifèria}

Número 18(2), diciembre 2013

http://revistes.uab.cat/periferia

mayor intercambio poblacional en el norte, en donde se conformaron redes más complejas de intercambio e interacción. En el centro de Patagonia, entre la cuenca del río Gallegos y el río Negro o el río Colorado no existieron barreras importantes a la interacción y al intercambio, como no fuese el factor condicionante impuesto por la simple distancia entre comunidades. En el momento del impacto colonial, migraciones desde el oeste cordillerano modificaron el patrón de distancias recorridas y de variabilidad interna en aquellas poblaciones patagónicas que recibieron el impacto de este flujo durante un tiempo prolongado.

\section{Etnogénesis "moderna" y orígenes de la territorialización}

Algunos autores sugieren vincular el origen de la territorialización y de las formas "modernas" de interacción social con cambios ecológicos que afectaron la movilidad de poblaciones alrededor del primer milenio de nuestra era. El cambio climático producido durante la Anomalía Climática Medieval (1021-1228 DC) habría provocado situaciones de estrés ambiental cuyas consecuencias sociales conducirían a definir nuevas estrategias como migración, conflicto y aumento del desarrollo tecnológico mediante el cual se pudieran maximizar los recursos disponibles. El incremento de aridez habría sido la causa de la reducción de fuentes de agua potable, restringiendo espacialmente y concentrando los movimientos animales y asentamientos, y conduciendo a una mayor especialización social en el uso del espacio físico. La apertura de las redes de intercambio social pudo haber compensado la reducción de la movilidad de patrones de residencia y la agrupación de asentamientos. Arqueológicamente, la constatación de altas tasas de entierros reutilizados en una misma área sugiere grupos más estables, ligados a un territorio específico (Goñi 2002). Del mismo modo, la concentración de lugares con arte rupestre podría sugerir la agregación de diferentes grupos en lugares específicos (Boschín 2010).

La creciente territorialización dio como resultado una mayor intensidad y frecuencia en las interacciones sociales entre poblaciones, acelerando la trasformación de los medios tradicionales de reproducción social y del orden político. Así se habría 


\section{perifèria}

Número 18(2), diciembre 2013

http://revistes.uab.cat/periferia

intensificado la tendencia hacia una mayor centralización en los mecanismos de toma colectiva de decisiones, una creciente jerarquización social, inherente al incremento en tamaño de los grupos, al desarrollo de la división social del trabajo y a la composición socialmente más diversa de las poblaciones (Barceló et al. 2009, Barrientos y Pérez 2004, Mazzanti 2006).

\section{Jinetes de la estepa patagónica}

No es hasta los siglos XVIII y XIX cuando las relaciones sociales de producción comenzaron a perfilar características fuertemente relacionadas con la diversidad y la desigualdad social (Mazzanti 2006, Nacuzzi 1998, 2007). Tradicionalmente, la introducción del caballo ha sido considerada un elemento clave para explicar el cambio social ocurrido en momentos históricos, aun cuando la idea de un "complejo ecuestre" es criticable por enfatizar una explicación causal simple y reduccionista del cambio social, que entiende la superficialidad del fenómeno y no las bases materiales del mismo. Las poblaciones septentrionales adoptaron el caballo desde la primera aparición del ganado cimarrón, a lo largo de la segunda mitad del siglo XVI, y demostraron marcadas transformaciones a nivel económico, especializándose en ganadería equina y bovina e intercambio regional de ganado a gran escala desde el siglo XVIII. Así es que al norte del río Santa Cruz habitaban en el siglo XVIII pueblos ecuestres, mientras al sur de dicho río en ese momento había pocos caballos en propiedad de caciques. Los grupos meridionales patagónicos incorporaron caballos tardíamente en su sistema productivo; continuaron siendo nómadas cazadores-recolectores, con caballos, durante el siglo XIX.

La adopción del caballo amplió territorios de caza, facilitó movimientos, aumentó el rango y la frecuencia de desplazamientos nomádicos y enriqueció el sistema productivo con nuevos medios y productos. Por otro lado, generó nuevas formas de relación intergrupal al convertirse el caballo en un bien necesario de adquisición difícil. Su rol en el pago de compromisos matrimoniales o en situaciones de agravios, en rituales, desplazó símbolos tradicionales y multiplicó los encuentros interétnicos, que se hicieron más frecuentes, más intensos y a mayores distancias. 


\section{perifèria}

Número 18(2), diciembre 2013

http://revistes.uab.cat/periferia

Como consecuencia, el nomadismo consustancial a las poblaciones cazadorasrecolectoras se transformó en un sistema de desplazamientos estables y regulares con base mercantil, en la que ganaderos indígenas se apropiaron del ganado de la Pampa argentina y abastecieron los mercados coloniales de la costa del Pacífico, haciendo interactuar a poblaciones a ambos lados de la cordillera en un circuito de bienes, ideas y gentes que ponía en contacto puntos alejados entre sí por varios miles de kilómetros. Los mecanismos políticos de control social comenzaron a expresarse desde la regulación de los derechos territoriales y de los mecanismos de reproducción social. La autoridad se fue restringiendo e individualizando, legitimizándose por medio de ritos y símbolos. Determinados caciques septentrionales, únicos interlocutores entre la autoridad gubernamental y sus pueblos, fueron transformando su figura, haciéndose más visible y enriqueciéndose con ganado, regalos, agasajos, recibidos de las autoridades al cumplir con su rol de mensajeros.

Basando su trabajo en los estudios histórico-económicos, Raúl Mandrini (Mandrini 1988, 1992a) ha analizado esta amplia red de intercambio y movilización de recursos, sugiriendo que el control de este circuito estaba en manos de cacicatos consolidados, que poseerían atribuciones relevantes en lo que se refiere al liderazgo político, al rol de intermediación con las autoridades coloniales, a la posesión de bienes suntuarios de prestigio y a la redistribución, legitimando su poder en base a la pertenencia a una elite familiar poseedora de los derechos de sucesión.

El conflicto con el estado colonial y el incremento de la competitividad entre los grupos indígenas disparó mecanismos de fusión social, migración y conformación de jefaturas, afianzando procesos de etno-génesis, resultando en la desarticulación de la organización política de las etnias del período pre contacto ante la necesidad de generar y consolidar nuevas estructuras políticas de asociación, resistencia y coalición. Podemos interpretar las descripciones de los viajeros del siglo XIX (referencias editadas y comentadas en Embon, 1950) en términos de una configuración social con dos niveles de jerarquía, con el nivel superior usualmente detentado por hombres y, ocasionalmente, por mujeres. En grupos de más de 1.000 personas emerge el "cacicazgo" o jefatura, entendida como la estructura de 


\section{perifèria}

Número 18(2), diciembre 2013

http://revistes.uab.cat/periferia

poder que reordena al conjunto de las relaciones sociales a partir del quiebre de las relaciones de reciprocidad, la formación de un aparato burocrático e incremento de los contactos con el estado colonial y la sociedad de mercado.

Para la segunda mitad del siglo XIX en la Patagonia noroccidental, Julio Vezub (2009) ha analizado específicamente la Gobernación Indígena del País de las Manzanas, una entidad indígena gobernada por Valentín Sayhueque, considerado un ejemplo paradigmático en cuanto al rol coercitivo ejercido por los caciques norpatagónicos. El estudio de la correspondencia entre el cacique indígena y el estado argentino, permitió a este investigador establecer los fuertes vínculos familiares existentes entre las diferentes etnias indígenas, observándose cómo se articuló una organización política compleja y jerárquica.

La naturaleza de los intercambios de bienes, ideas y personas y las distancias recorridas por las poblaciones meridionales (a orillas del estrecho de Magallanes) en su búsqueda de mercados septentrionales (provincia de Buenos Aires) pudo haber sido la causa de la hibridación y mestizaje de poblaciones, fenómeno caracterizado por la expansión de lenguas del tronco lingüístico mapudungun desde su región original al oeste de los Andes hasta las costas del Atlántico. Esta lengua se convirtió en común entre diferentes poblaciones, integrándolas alrededor de un lenguaje similar y una economía similar (intercambio de ganado bovino y caballar). Desde el siglo XVIII, pero con más intensidad desde inicios del XIX, las influencias del oeste modificaron muchos aspectos económicos, sociales, lingüísticos, políticos e ideológicos de poblaciones anteriormente diferenciadas cultural y/o lingüísticamente al configurarse nuevas redes de interacción social.

La tardía homogeneización de lenguas y culturas de los habitantes de las estepas patagónicas fue probablemente causada por un incremento en la frecuencia y en la intensidad de mecanismos de intercambio a larga distancia. La diferenciación de bienes de entierros, la concentración de objetos de prestigio en tumbas infantiles, la circulación de materia prima y objetos a través de redes de intercambio de largas distancias y el tamaño amplio de algunos asentamientos son también características datadas antes del contacto europeo, o más tarde pero siempre anteriores a la adopción del caballo. 


\section{perifèria}

Número 18(2), diciembre 2013

http://revistes.uab.cat/periferia

\section{Conclusiones}

La concepción de poblaciones cerradas, inmutables, aún pervive hoy en día, lo que impide concebir la transformación histórica de los indígenas patagónicos y aceptar el mestizaje (del Castillo et al. 2011).

En contra del evolucionismo simplista de la tradición etnográfica clásica de la región, no deberíamos imaginar a las poblaciones autóctonas de Patagonia en la base de una pirámide o en el punto de partida de una escala de desarrollo posterior. Se trata de sociedades diferentes de aquellas que construyeron su economía sobre la base del control y la manipulación de la reproducción vegetal y animal. Esa diferencia no debe leerse en términos de tipos excluyentes, sino que debe ser entendida como una gradación, un continuo.

La actual marginación y pérdida de derechos de los hoy denominados pobladores autóctonos es propia de la expansión del capitalismo, la proletarización y, también, de su esclavización. La ausencia de etnónimo, como no sea la expresión "paisano", expresa un interés por desetnizar la realidad. Por otro lado, la aparición de nuevas formas de identidad (el neo-etnónimo "mapuche-tehuelche") muestra la necesidad de lucha política en una nueva situación. Las formas contemporáneas de interacción económica: el robo de tierras, el traslado y relocalización de poblaciones configuran mecanismos restrictivos que estigmatizan a una parte de la población y les imponen formas de interacción que determinan su propia reproducción social: su misma marginación se reproduce junto con la identidad del marginado.

\section{Agradecimientos}

Nuestros trabajos de investigación están financiados por el Ministerio de Ciencia e Innovación: HAR2012-31036 y CSD2010-00034 (Convocatoria Ingenia-Consolider). 


\section{perifèria}

Número 18(2), diciembre 2013

http://revistes.uab.cat/periferia

\section{Bibliografía}

Barberena, R. (2008). Arqueología y biogeografía humana en Patagonia Meridional. Buenos Aires: Publicaciones Sociedad Argentina de Antropología.

Barceló, J.A; del Castillo Bernal, F., Mameli, L.; Moreno, E. and Videla, B. (2009). Where does the South Begin? Social Variability at the Southern top of the World. Arctic Anthropology, vol. 45, no 2, pp. 46-71.

Barceló, J.A; del Castillo Bernal, F., Mameli, L.; Moreno, E. and Sáez, A. (2011). Patagonia: Del Presente Etnográfico al Pasado Arqueológico. Revista de Arqueología Iberoamericana, vol. 9, no1, pp. 6-39.

Barrientos, G. e I. Pérez (2004). La expansión y dispersión de poblaciones del norte de Patagonia durante el Holoceno tardío: evidencia arqueológica y modelo explicativo. Contra Viento y Marea. Arqueología de Patagonia. M. Civalero, P. Fernández y A. Guraieb (eds.): 17-96. Buenos Aires: INAPL- Sociedad Argentina de Antropología.

Borrero, L.A., Charlin, J., Barberena, R., Martin, F.M., Borrazzo, K. and L'Heureux, L. (2008). Circulación humana y modos de interacción al sur del río Santa Cruz. En Arqueología del extremo sur del continente americano. Resultados de nuevos proyectos. L. Borrero y N. Franco (Comps.) CONICET e Instituto Multidisciplinario de Historia y Ciencias Humanas, pp. 155-175.

Boschín, M-T. (2010). Tierra de Hechiceros. Arte Indígena de Patagonia Septentrional Argentina. Ediciones de la Universidad de Salamanca.

Boschín, M.T. y Andrade. A. (2011). Poblamiento de Patagonia septentrional Argentina durante el Holoceno tardío: paleoambientes e imperativos sociales. Zephirus, LXVIII, pp. 41-61.

del Castillo Bernal, F. (2012). Modelando la heterogeneidad étnica y la diversidad cultural en arqueología de cazadores recolectores patagónicos. Aproximaciones desde la Simulación Computacional y los Modelos Basados en Agentes. Ph.D. Dissertation. Universidad Autónoma de Barcelona. 


\section{perifèria}

Número 18(2), diciembre 2013

http://revistes.uab.cat/periferia

del Castillo Bernal, F., Barceló, J.A. (2014). Simulando etnicidad y etnogénesis en grupos cazadores-recolectores. Patagonia como caso de estudio. Libros de la Serie de Arqueología Americana, British Archaeological Report - BAR (en prensa).

del Castillo Bernal, F., Mameli, L. y Barceló, J.A. (2011). La arqueología patagónica y la reconstrucción de la historia indígena. Revista Española de Antropología Americana, vol. 41, n¹, pp. 27-50.

Embon, A. (1950) Fuentes históricas, con noticias etnográficas y arqueológicas del indígena patagón. (manuscrito). Tesis de Doctorado en Historia. Facultad de Humanidades y Ciencias de la educación. Universidad Nacional de La Plata (Argentina).

Gómez Otero, J. (2007). Dieta, uso del espacio y evolución en poblaciones cazadoras-recolectoras de la costa centro-septentrional de Patagonia durante el Holoceno medio y Tardío. Tesis Doctoral, Facultad de Filosofía y Letras, Universidad de Buenos Aires.

Goñi, R.A. (2000-2002). Poblamiento humano y paleoambiente. Su cronología en la cuenca de los lagos Cardiel y Strobel. Cuadernos del Instituto Nacional de Antropología y Pensamiento Latinoamericanos, no 19, pp. 669-671.

Mandrini, R. (1991). Procesos de especialización regional en la economía indígena pampeana (XVIII-XIX), el caso del suroeste bonaerense. Boletín americanista, no 41, pp. 113-136.

Mandrini, R. (1992). Indios y Fronteras en el área pampeana (siglos XVI-XIX) Balance y perspectivas. Anuario IEhS, 7, pp. 59-72.

Mazzanti, D.L. (2006). La constitución de territorios sociales durante el Holoceno tardío. El caso de las sierras de Tandilia, Argentina. Relaciones de la Sociedad Argentina de Antropología XXXI, pp. 277-300.

Moreno, E. (2008) Arqueología y etnohistoria de la costa patagónica central en el Holoceno tardío. Rawson: Fondo Editorial provincial, Secretaría de Cultura, Chubut. 


\section{perifèria}

Número 18(2), diciembre 2013

http://revistes.uab.cat/periferia

Nacuzzi, L. (1998). Identidades impuestas. Tehuelches, Auca y Pampas en el Norte de la Patagonia. Buenos Aires: SAA.

Nacuzzi, L. (2007). Los grupos nómades de la Patagonia y el Chaco en el siglo XVIII: identidades, espacios, movimientos y recursos económicos ante la situación de contacto. Una reflexión comparativa. Chungara, vol. 39, no 2, pp. 221-234.

Perez, S.I. (2011). Poblamiento humano, diferenciación ecológica y diversificación fenotípica en América. Runa, vol. 32, no 1, pp. 83-104.

Prates, L. (2008). Los antiguos habitantes del río Negro desde una visión arqueológica. Buenos Aires: Ediciones de la Sociedad Argentina de Antropología.

Vezub, J. (2009). Valentín Saygüeque y la gobernación indígena de Las Manzanas.

Poder y etnicidad en la Patagonia septentrional (1860-1881). Buenos Aires: Prometeo Libros. 